\title{
ORIGINAL ARTICLE Sexual problems of women with spinal cord injury in Turkey
}

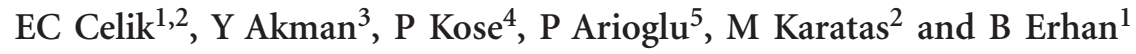

Objectives: Spinal cord injury (SCI) is a traumatic event that affects many facets of the injured people's lives. One aspect is sexual functioning. The purpose of this study is to identify the sexual problems of women with $\mathrm{SCl}$ and determine their level of knowledge about sexuality.

Methods: Twenty-six women with SCl for longer than 6 months were evaluated. Demographic information, sexual experiences were surveyed. Patients were also asked if and how they received sexual health consultation after SCI. Female Sexual Function Index (FSFI) and Beck Depression Inventory were evaluated.

Results: In this study, average age of the women with SCI was 32.96 $\$ 8.23$ years (22-50 years). Eight patients had regular sexual intercourse while one married woman did not have any sexual relationship after SCl. Twenty-four of the patients in the study received no information about pregnancy or sexual health after SCI. All women were willing to receive information about sexuality after SCI. These patients expected the doctors to start the conversation about sexuality rather than asking about it. FSFI survey revealed that all the patients had sexual dysfunction.

Conclusion: Sexual rehabilitation should thus be fully addressed in all spinal units and rehabilitation centers, along with other aspects of rehabilitation.

Spinal Cord (2014) 52, 313-315; doi:10.1038/sc.2013.161; published online 14 January 2014

Keywords: spinal cord injury; women; sexual problems

\section{INTRODUCTION}

Spinal cord injury (SCI) is a traumatic event that affects many facets of the injured person's life, including sexual life. ${ }^{1,2}$ Sexuality constitutes a fundamental part of people's lives, integrating physical, emotional, intellectual and social aspects. ${ }^{3}$

A long-term disability can have a profound impact on a woman's innate sense of sexuality, sexual function and, occasionally, fertility. Various myths about sexuality and disability in society, such as 'disabled women are asexual, only independently functioning women can handle a sexual relationship, disabled women cannot be mothers, disabled women who are single are celibate', results in the sexual well-being of disabled women being neglected. ${ }^{3-5}$

Comparatively little research on sexuality in the population with SCI focuses specifically on the sexual concerns of women. ${ }^{2,3,5,6}$ However, in recent years there has been growing acknowledgement of the sexual concerns of women with SCI. Despite this, the conveyance of this knowledge to the women with SCI appears to be insufficient. ${ }^{6}$ Previous research has shown that the majority of women with SCI are dissatisfied with the amount and the quality of information about sexual functioning and sex life provided at rehabilitation centers. ${ }^{1}$

The purpose of this study is to identify the sexual problems of women with SCI and determine their level of knowledge about sexuality and their condition in our country.

\section{MATERIALS AND METHODS}

As a university hospital, we conducted a seminar in the Bakirkoy Spinal Cord Injury Association about sexual problems of women with SCI. Before the seminar, we asked participating women with SCI to complete some questionnaires. Demographic information, including marital status before and after SCI, sexual experience, pregnancy, miscarriages and abortions, family members of the patients, were surveyed. Patients were asked if they had any sexual health consultation after SCI, by whom they would prefer consultation to be offered and when this should be offered. Female Sexual Function Index (FSFI) and Beck Depression Inventory (BDI) were also evaluated. FSFI is a self-report measure of female sexual function, which includes six domain characteristics of female sexual function (desire, arousal, lubrication, orgasm, satisfaction and pain) with 19-item questionnaire. The total scores of FSFI could be between 2 and 36. Total score of FSFI $<26.55$ delineates subjects with female sexual dysfunction from those without female sexual dysfunction. ${ }^{7}$ Validity and reliability of FSFI Turkish version was assessed by Oksuz and Malhan. ${ }^{8}$

The aim of the BDI scale is to measure depression symptoms on a self-report basis. It has been developed by Beck et al. ${ }^{9}$ Validity and reliability of its Turkish version have been demonstrated by Hisli. ${ }^{10}$ The score of $\mathrm{BDI}$ is commentated as 0: no depression; and 1: low, 2: median, 3: high level depression.

In this study, women with SCI for longer than 6 months were evaluated. Patients with genitourinary infections, catheters, pressure ulcers, spasticity of Ashworth score 3 or more, and those who were illiterate or had difficulty understanding the questions, were not included in the study.

\footnotetext{
${ }^{1}$ Physical Medicine and Rehabilitation Department, Istanbul Physical Medicine and Rehabilitation Training and Research Hospital, Istanbul, Turkey; ${ }^{2}$ Physical Medicine and Rehabilitation Department, Faculty of Medicine, Baskent University, Istanbul, Turkey; ${ }^{3}$ Urology Department, Faculty of Medicine, Baskent University, Istanbul, Turkey; ${ }^{4}$ Department of Psychiatry, Clinic Psychologist, Faculty of Medicine, Baskent University, Istanbul, Turkey and ${ }^{5}$ Obstetrics and Gynecology Department, Faculty of Medicine, Baskent University, Istanbul, Turkey

Correspondence: Dr EC Celik, Istanbul Physical Medicine and Rehabilitation Training Hospital, Atakent mah 3 Etap D28 Blok Daire 9 Kucukcekmece, Istanbul 34180 , Turkey. E-mail: evrimcoskuncelik@gmail.com
}

Received 27 June 2013; revised 15 November 2013; accepted 19 November 2013; published online 14 January 2014 
In addition to descriptive statistics, Mann-Whitney $U$-test, $\chi^{2}$ test and Pearson correlation tests were done. At the statistical analysis of the data, $P<0.05$ was considered statistically significant.

We certified that all applicable institutional and governmental regulations concerning the ethical use of human volunteers were adhered to during the course of this research.

\section{RESULTS}

In this study, average age of the women with SCI was $32.96 \pm 8.23$ years (22-50 years). Patients were a mean of $168 \pm 88.73$ months postinjury (36-420 months).

Marital statuses were: 6 married, 16 single and 4 widows. After SCI, two patients got divorced and two patients got married. One divorced patient was paraplegic and the other was tetraplegic. Both already had one child before getting divorced. The two newly married patients were paraplegic. Single or widow patients were not living alone but with other family relatives. Also they did not go anywhere unaccompanied. Only two patients had personal income and the rest of them were dependent on family members, economically (Table 1).

Eight patients with SCI had regular sexual intercourse, whereas one married woman did not have any sexual relationship after SCI. Only one woman after SCI had a baby, and pregnancy of another patient resulted in a miscarriage.

Twenty-four patients in the study received no information about pregnancy or sexual health after SCI. Two patients received information only when they actively demanded it, not as part of a routine consultation. All women were willing to receive information about sexuality after SCI and most of them would have preferred to receive this information while they were still hospitalized. Of the 26 patients with SCI, 1 preferred to receive information about sexuality and pregnancy from family members, 1 from nurses and 24 from doctors. These patients expected the doctors to start the conversation about sexuality rather than asking about it.

The patients who had sexual affairs were grouped as sexually active patients and who did not have sexual affairs were grouped as sexually inactive patients. There were only eight sexually active patients. There were no statistically significant differences in age, time after injury, between women with and without sexual activity. Sexually active women demanded information more frequently and this was statistically significant (Table 2).

FSFI survey revealed that five of eight sexually active patients had sexual dysfunction. Overall, 19 women had regular menstrual cycles, 5 reported irregular menstruation and 2 were in menopause.

When we analyze the BDI, only 3 out of the 8 sexually active patients $(38 \%)$ had depression, whereas 14 out of the 18 sexually inactive patients $(78 \%)$ had depression. Values of $P=0.04$ were considered to as statistically significant differences. Also negative correlation was seen between depression level and FSFI score in all patients $(P=0.011, r=-0.491)$.

\section{DISCUSSION}

Sexuality in women with SCI has largely been neglected. ${ }^{2,3,11,12}$ Issues relating to sexual functioning and sex life in women after SCI have received relatively little attention in the scientific literature or in clinical rehabilitation efforts. ${ }^{1,2,13}$ One reason may be the male dominance among individuals with SCI. Female sexual dysfunction is less problematic than for males with SCI; the majority of paraplegic or tetraplegic women will continue to menstruate, ovulate and may reproduce. . $^{2,11}$

In our study, all patients wanted to receive information about sexuality, sexual life, fertility and pregnancy. Many authors have also
Table 1 Demographics and clinical characteristics of all women $(n=26)$

\begin{tabular}{|c|c|}
\hline Demographics & Subjects $(\mathrm{n}=26)$ \\
\hline Age (mean \pm s.d.) & $32.96 \pm 8.23(\min 22, \max 50)$ \\
\hline SCl time & $168 \pm 88.73$ months (range $36-420$ ) \\
\hline \multicolumn{2}{|l|}{ Level of injury: } \\
\hline Paraplegia ( $n$ ) & 24 \\
\hline Tetraplegia $(n)$ & 2 \\
\hline \multicolumn{2}{|l|}{ Marital status: } \\
\hline Married $(n)$ & 6 \\
\hline Single $(n)$ & 16 \\
\hline Widow $(n)$ & 4 \\
\hline \multicolumn{2}{|l|}{ After SCl: } \\
\hline New marriage & 2 (Both were paraplegia) \\
\hline Divorced & 2 (1 Tetraplegia and other was paraplegia) \\
\hline \multicolumn{2}{|l|}{ After SCl: } \\
\hline Newborn & 1 \\
\hline Pregnancy (abortion) & 1 \\
\hline \multicolumn{2}{|l|}{ Level of education: } \\
\hline Grade 8 or lower $(n)$ & 15 \\
\hline Grade 8 above $(n)$ & 11 \\
\hline
\end{tabular}

Abbreviation: $\mathrm{SCl}$, spinal cord injury.

Table 2 Comparison of age, $\mathrm{SCl}$ time and sexual demand of sexually active and inactive women

\begin{tabular}{lccc}
\hline & Sexual active & Sexual inactive & P-value \\
\hline Age & $36.38 \pm 6.54$ & $31.44 \pm 8.60$ & 0.127 \\
SCl time (month) & $162.00 \pm 79.34$ & $163.83 \pm 92.03$ & 0.959 \\
Sexual demand (FSFI) & $4.72 \pm 1.08$ & $3.03 \pm 1.12$ & $0.003^{*}$ \\
\hline
\end{tabular}

Abbreviations: FSFI, Female Sexual Function Index; SCI, spinal cord injury. ${ }^{*} P<0.05$.

noted that most women do not receive any information about sexuality at any time after injury. Kreuter et al. ${ }^{6}$ reported that $61 \%$ of patients with SCI receive no information about sexuality. ${ }^{2}$ At the time of investigation, $40 \%$ expressed a wish to receive information. Many women pointed out the importance of being offered the opportunity to talk to someone with good knowledge about the impact of a SCI on sexuality and sexual life. ${ }^{2,6}$ Most women with SCI would have liked more sexual counseling during rehabilitation. ${ }^{14}$

Our study has shown that $42.31 \%$ of patients preferred to receive this information while still at the hospital for rehabilitation. Many women also mentioned that the information was not given too soon after the injury, but that they should be informed about whom they could talk to when the need arose. ${ }^{6}$ Sex information/education programmes should be an integral component of rehabilitation and during life-long follow-up, because sexual needs and concerns may change over time. ${ }^{1,2}$ Sexual satisfaction is not static and holds great subjectivity, and may continue to evolve over time for all individuals. Given this, continued opportunity for sexual counseling is required, even after the women have left the rehabilitation centers and returned to their homes and partners. These considerations support the need 
for services that provide lifelong interventions and assessment of these patients through a holistic approach, including a variety of specializations that are relevant to sexual rehabilitation. ${ }^{1,2}$

Patients in our study expected the doctors to start the conversation about sexuality rather than actively demanding information and $92.3 \%$ of patients preferred to be informed by doctors. Unfortunately, many physicians fail to initiate such discussion. This implies that it is not a straightforward matter for a disabled woman to be a sexual person. ${ }^{4}$ The importance of validating a disabled patient's sexual identity must be emphasized. The physician can accomplish this by initiating discussion of the woman's sexual function and of safer sexual practices. ${ }^{14}$ In Forsythe and Horsewell ${ }^{14}$ study revealed that women with SCI expect clinicians to initiate discussions about sex and sexuality, whereas clinical personnel expect the women to make the relevant remarks.

Women need more information concerning sexuality at the initial period of rehabilitation following SCI. That this information is made available should be the responsibility of the clinic, not of the individual patient. ${ }^{14}$ If the goal of rehabilitation is to restore the injured person as fully as possible to their premorbid level of functioning, this must apply to sexuality as well. It is important that all staff have adequate knowledge about sexual functioning after SCI and feel comfortable raising the issue of sexuality to allow the patients opportunities to discuss this topic. ${ }^{1,2}$ Although demand is growing for education and training of health-care professionals in the field of sexual rehabilitation, unfortunately it is still a discipline that does not exist in many rehabilitation centers and countries. ${ }^{15}$

Several studies have shown that divorce rates of women with SCI differ from the general population, although others have not confirmed this finding. Divorce rates have been reported to be anywhere from 8 to $48 \%{ }^{16}$ In our report, $33.33 \%$ of women married before SCI got divorced. Being more dependent, having no children and having been injured within $<3$ years, carry a higher risk for getting divorced. ${ }^{16}$ In our study, one of the divorced women was tetraplegic and she got divorced immediately after injury. Both the divorced women had one child each.

In our study, the level of sexual desire was found to be higher in sexually active women. Kreuter ${ }^{6}$ have reported that many women with SCI experienced a major decline in sexual desire.

Studies have shown that $53-67 \%$ of women following SCI are sexually active. ${ }^{3}$ Sexual satisfaction has been shown to decrease after SCI, but desire does not diminish. ${ }^{1,6,17}$ Matzaroglou et al. ${ }^{12}$ have found that women with severe SCI had no statistically significant difference with respect to desire, satisfaction, pain/comfort but had less orgasms and lubrication compared with healthy controls.

Kreuter et al. ${ }^{1}$ have shown that most women with SCI continue to be sexually active after their injury and that they consider sex to be an important part of their lives. In all, $40-80 \%$ of women continued to be sexually active after injury, but to a much lesser extent than before injury. ${ }^{3,5,6}$ Many authors report that more than three-quarters of women with SCI continued to be sexually active after the injury. ${ }^{18}$

Lombardi et $a l^{2}{ }^{2}$ indicated that neurologic conditions might negatively impact on sexual life due to the lack of, or difficulties involved in, interpersonal-social relations. In this study, patients with SCI were living with family members and could not go outside unaccompanied. So they had a small chance to build social relations with opposite sex, in Turkey.

Harrison et al. ${ }^{19}$ represented that higher level of depression was associated with negative feelings about sexual activity. This study demonstrated that depression was more common for sexually inactive women, also. But it was not clear whether depression caused sexual inactiveness or vice versa. We must research relationship between depression and sexual dysfunction in SCI women in next studies.

The rehabilitation of sexual function in women following SCI is aimed at facilitating a form of sexual expression that is both acceptable and satisfying to the women. ${ }^{14}$ It should be fully addressed in all spinal units and rehabilitation centers, along with other aspects of rehabilitation.

\section{DATA ARCHIVING}

There were no data to deposit.

\section{CONFLICT OF INTEREST}

The authors declare no conflict of interest.

1 Kreuter M, Taft C, Siösteen A, Biering-Sorensen F. Women's sexual functioning and sex life after spinal cord injury. Spinal Cord 2011; 49: 154-160.

2 Lombardi G, Del Popolo G, Macchiarella A, Mencarini M, Celso M. Sexual rehabilitation in women with spinal cord injury: a critical review of the literature. Spinal Cord 2010; 48: 842-849.

3 Ferreiro-Velasco ME, Barca-Buyo A, de la Barrera SS, Montoto-Marqués A Vázquez XM, Rodríguez-Sotillo $A$. Sexual issues in a sample of women with spinal cord injury. Spinal Cord 2005; 43: 51-55.

4 Basson R. Sexual health of women with disabilities. CMAJ 1998; 25: 359-362.

5 Jackson AB, Wadley V. A multicenter study of women's self-reported reproductive health after spinal cord injury. Arch Phys Med Rehabil 1999; 80: 1420-1428.

6 Kreuter M, Siösteen A, Biering-Sorensen F. Sexuality and sexual life in women with spinal cord injury: a controlled study. J Rehabil Med 2008; 40: 61-69.

7 Rosen R, Brown C, Heiman J, Leiblum S, Meston C, Shabsigh R et al. The Female Sexual Function Index (FSFI): a multidimensional self-report instrument for the assessment of female sexual function. J Sex Marital Ther 2000; 26: 191-208.

8 Oksuz E, Malhan S. Reliability and validity of the female sexual function index in turkish population. Sendrom 2005; 17: 54-60.

9 Beck AT, Ward $\mathrm{CH}$, Mendelson M, Mock J, Erbaugh J. An inventory for measuring depression. Arc Gen Psychiatry 1961; 4: 561-571.

10 Hisli N. Beck Depresyon Envanterinin Geçerliliği Üzerine Bir Çalışma (A study on the validity of Beck Depression Inventory in Turkish). Psikoloji Dergisi 1988; 6: 118-126.

11 Lombardi G, Mondaini N, Macchiarella A, Del Popolo G. Female sexual dysfunction and hormonal status in spinal cord injured patients. J Androl 2007; 28: 722-726.

12 Matzaroglou C, Assimakopoulos K, Panagiotopoulos E, Kasimatis G, Dimakopoulos P, Lambiris E. Sexual function in females with severe cervical spinal cord injuries: a controlled study with the Female Sexual Function Index. Int J Rehabil Res 2005; 28. 375-377.

13 Abramson CE, McBride KE, Konnyu KJ, Elliot SL, The Scire Research Team. Sexual health outcome measures for individuals with a spinal cord injury: a systematic review. Spinal Cord 2008; 46: 320-324.

14 Forsythe $\mathrm{E}$, Horsewell JE. Sexual rehabilitation of the women with a spinal cord injury. Spinal Cord 2006; 44: 234-241.

15 Sharma SC, Sing R, Dogra R, Gupta SS. Assesment of sexual functions after spinal cord injury in Indian patients. Int J Rehabil Res 2006; 29: 17-25.

16 Kreuter M. Spinal cord injury and partner relationships (scientific review). Spinal Cord 2000; 38: 2-6.

17 Sipski ML, Alexander CJ, Gomez-Marin O, Grossbard M, Rosen R. Effects of vibratory stimulation on sexual response in women with spinal cord injury. J Rehabil Res Dev 2005; 42: 609-616.

18 McAlon S. Improving sexual rehabilitation services the patient's perspective. Am J Occup Ther 1996; 50: 826-834.

19 Harrison J, Glass CA, Owens RG, Soni BM. Factors associated with sexual functioning in women following spinal cord injury. Paraplegia 1995; 33: 687-692. 